\title{
Establishing a Baseline: Health Information Technology Adoption among Family Medicine Diplomates
}

\author{
Andrew Bazemore MD, MPH, Matthew Burke, MD, Imam Xierali, PhD, \\ Stephen Petterson, PhD, Jason Rinaldo, PhD, Larry A. Green, MD, and James Puffer, MD
}

The Office of the National Coordinator and recent federal policy have dramatically expanded incentives for adoption and "meaningful use" of electronic health records (EHRs). However, little reliable information regarding adoption rates in primary care, and some concern exists about lagging adoption rates beyond large group practices. ${ }^{1}$

Reported EHR adoption rates among family physicians - the largest and most widely distributed group of primary care providers-vary widely. We used a unique census survey that captured self-reported use of EHRs among this critical cohort, and had a $100 \%$ response rate among family medicine diplomats. Specifically, we used data from diplomates who were applying for the maintenance of certification (MOC) examination (part III, cognitive assessment) during the years 2006 through $2009(\mathrm{n}=8263$, $\mathrm{n}=9507, \mathrm{n}=9692$, and $\mathrm{n}=7941$, respectively). We stratified the data along the 2003 Rural Urban Continuum Codes to determine whether there would be variation with increasing rurality.

The rate of EHR adoption among family physicians rose significantly between $2006(37 \%)$ and 2009 (55\%) (Figure 1). The 4-year (2006-2009) pooled adoption rate across the rural to urban continuum revealed a slight but statistically insignificant decrease in adoption with increasing rurality, consistent with evidence that rural family physicians are keeping up with urban peers in MOC. ${ }^{2}$ However, significant variation at the state level was apparent.

This article was externally peer reviewed.

Submitted 6 January 2011; revised 26 January 2011; accepted 26 January 2011.

From the Robert Graham Center, Washington, DC (AB, IX, SP); the American Board of Family Medicine (ABFM) (JR, JP, LG); Georgetown University (MB).

Funding: none.

Conflict of interest: none declared.

Corresponding author: Andrew Bazemore, MD, MPH, Asst. Director, Robert Graham Center, 1350 Connecticut Avenue NW, Suite 201, Washington, DC 20036 (E-mail: abazemore@aafp.org).
Figure 1. Mean adoption of electronic health records, 2006-2009, where $1=$ most urban and $9=$ most rural. 2009 subjects include exam takers through April 2009.

Data are from responses to a mandatory survey required of all family physicians who take the cognitive testing component of American Board of Family Medicine recertification examination. NA, cases unable to be georeferenced to 2003 Rural Urban Continuum Codes.

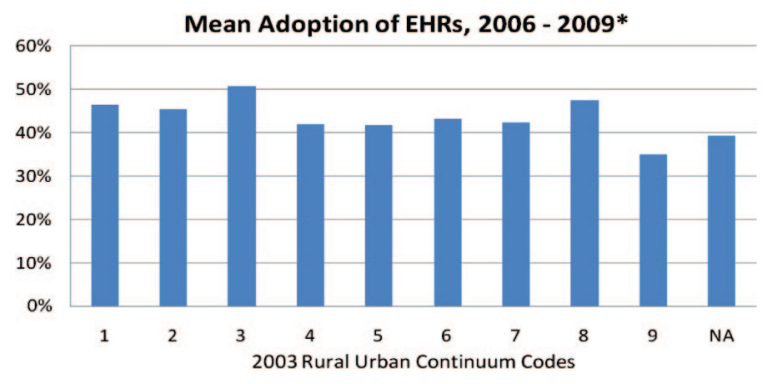

A majority of board-certified family physicians in the United States now use EHRs. The most rural of family physicians lag slightly behind the national adoption frequency, but 4-year trends suggest similar rates of uptake. Though board-certified family physicians may differ from those who do not maintain certification, understanding uptake among this cohort is critical because MOC and the adoption of health information technology both are essential elements of quality improvement in primary care. Although further monitoring of adoption trends is important, the mounting challenge will not be adoption but the sufficiency of EHRs to help family physicians take better care of their patients.

\section{References}

1. DesRoches CM, Campbell EG, Rao DR, et al. Electronic health records in ambulatory care-a national survey of physicians. N Engl J Med 2008;359:50-60.

2. Bazemore AW, Xierali IM, Petterson SM, et al. American Board of Family Medicine (ABFM) maintenance of certification: variations in self assessment modules uptake within the 2006 cohort. J Am Board Fam Med 2010;23:49-58. 